\title{
PARC syndrome
}

INSERM

\section{Source}

INSERM. (1999). Orphanet: an online rare disease and orphan drug data base. PARC syndrome. ORPHA:2825

PARC syndrome is a rare genetic developmental defect during embryogenesis syndrome characterized by the association of congenital poikiloderma $(P)$, generalized alopecia $(A)$, retrognathism (R) and cleft palate (C). There have been no further descriptions in the literature since 1990. 